Asian Spine Journal Vol. 6, No. 4, pp 241 248, 2012

http://dx.doi.org/10.4184/asj.2012.6.4.241

\title{
Cervical Pedicle Screw Fixation Combined with Laminoplasty for Cervical Spondylotic Myelopathy with Instability
}

\author{
Masashi Uehara, Jun Takahashi, Nobuhide Ogihara, Hiroki Hirabayashi, Hiroyuki Hashidate, \\ Keijiro Mukaiyama, Masayuki Shimizu, Hiroyuki Kato
}

Department of Orthopaedic Surgery, Shinshu University School of Medicine, Matsumoto, Japan

Study Design: A retrospective study.

Purpose: To evaluate the surgical results of cervical pedicle screw (CPS) fixation combined with laminoplasty for treating cervical spondylotic myelopathy (CSM) with instability.

Overview of Literature: Cervical fixation and spinal cord decompression are required for CSM patients with instability. However, only a few studies have reported on CPS fixation combined with posterior decompression for unstable CSM patients.

Methods: Thirteen patients that underwent CPS fixation combined with laminoplasty for CSM with instability were evaluated in this study. We assessed the clinical and radiological results of the surgical procedures. The Japanese Orthopedic Association (JOA) scoring system was used to evaluate the clinical results. The percentages of slip, difference in slip angle between maximum flexion and maximum extension of unstable intervertebrae, and perforation rate of CPS were evaluated.

Results: The mean JOA scores before surgery, immediately after surgery, and at final follow-up were 9.1, 13.3, and 12.6, respectively. The mean percentages of slip before surgery, immediately after surgery, and at final follow-up were 9.1\%, 3.2\%, and 3.5\%, respectively; there were significant improvements immediately after surgery and at final follow-up. The difference in slip angle between the maximum flexion and maximum extension of the unstable intervertebrae changed from $9.0^{\circ}$ before surgery to $1.6^{\circ}$ at the final follow-up. The perforation rate of CPS was $10.9 \%$.

Conclusions: The results suggest that CPS fixation combined with laminoplasty is an effective surgical procedure for treating CSM with instability.

Key Words: Cervical spondylosis, Myelopathy, Instability, Cervical fixation

\section{Introduction}

Cervical fixation and spinal cord decompression are required for cervical spondylotic myelopathy (CSM) patients with instability. Previously, anterior decompression and fusion (ADF) was performed to treat these patients $[1,2]$. Recent reports show that posterior laminectomy and lateral mass result in fusion $[3,4]$. Pedicle screws in the cervical spine and the cervicothoracic junction are increasingly being used because they improve biomechanical stability bet- ter than lateral mass screws and allow for shorter instrumentation with improved reposition capacities. We performed cervical pedicle screw (CPS) fixation combined with laminoplasty for treating CSM with instability. However, only a few studies report on CPS fixation combined with posterior decompression for unstable CSM patients. This study aimed to evaluate the clinical and radiological results of CPS fixation combined with laminoplasty for CSM with instability.

Received Oct 31, 2011; Revision Dec 17, 2011; Accepted Jan 17, 2012

Corresponding author: Jun Takahashi, MD

Department of Orthopaedic Surgery, Shinshu University School of Medicine, 3-1-1 Asahi, Matsumoto 390-8621, Japan

Tel: +81-263-37-2659, Fax: +81-263-35-8844, E-mail: jtaka@shinshu-u.ac.jp 


\section{Materials and Methods}

After approval by the Investigational Review Board of our hospital, this study included 13 patients ( 9 males, 4 females; mean age $73.5 \pm 7.2$ years) that underwent CPS fixation combined with laminoplasty for CSM with instability from April 1998 to April 2010. Patients that experienced trauma, rheumatoid arthritis (RA), destructive spondyloarthropathy (DSA), spinal tumor, or CSM with athetoid cerebral palsy were excluded from the study. All patients were followed up for more than 1 year.

\section{Indications}

Surgical treatment was indicated for patients with cervical myelopathy caused by spinal cord compression and cervical instability. Preoperatively, all patients had signs and symptoms of long-tract involvement such as gait disturbance, hand clumsiness, and hyperreflexia in the upper and lower extremities. White and Panjabi [5] define the radiographic instability of the cervical spine as a vertebral body slip length $>3.5 \mathrm{~mm}$ and a vertebral body angle change $>11^{\circ}$ between adjacent vertebral bodies. Regardless of whether the radiographic measurements of a patient met the above criteria, we performed posterior fixation using CPS if the patients' symptoms were severe but with mild spinal cord compression. We decided upon the extent of decompression level and pedicle screw fixation segment by evaluating the radiological instability and the existence of the spinal cord compression by magnetic resonance imaging.

\section{Operative technique}

At first, CPSs were inserted into pedicles in the unstable vertebral level using a computed tomography (CT)-based navigation system (Stealth Station and Stealth Station TREON, Medtronic, Sofamor Danek, Memphis, TN, USA). Expansive open-door laminoplasty [6] was performed in affected spinal cord levels. Holes were made using a 2-mmdiameter diamond speed drill in each of the lamina, and a suture was passed through the hole and tied to hinge the side rod. After decortications were performed on the lateral mass minced autologous bone was placed between the laminas and lateral mass, and the suture was tied securely. Patients were permitted to ambulate the day after surgery without a neck collar.

\section{Evaluation}

\section{1) Clinical outcomes}

The Japanese Orthopedic Association (JOA) scoring system [7] was used to evaluate cervical myelopathy before and immediately after surgery, and at the final followup. The recovery rate was calculated using the method of Hirabayashi et al. [6], which compares preoperative and postoperative JOA scores according to the following equation: recovery rate $(\%)=$ (postoperative score - preoperative score) $\times 100 /$ (full score - preoperative score). The occurrence of surgical complications, surgical time, and blood loss volume were also investigated.

\section{2) Radiologic evaluation}

Cervical sagittal alignment (i.e., the $\mathrm{C} 2-7$ lordotic angle) was measured according to tangential lines on the posterior edge of the $\mathrm{C} 2$ and $\mathrm{C} 7$ bodies from a lateral X-ray in a neutral position. The range of motion (ROM) of the cervical spine was calculated using X-rays during flexion and extension before and immediately after surgery, and at the final follow-up. \%ROM was calculated as follows: (postoperative $\mathrm{ROM} /$ preoperative $\mathrm{ROM}) \times 100$. Furthermore, the percentage of slip and difference of slip angle between the maximum flexion and maximum extension of unstable intervertebrae were measured. The percentage of slip is the ratio between the distance from a line parallel to the posterior portion of the vertebral body just below the slipped vertebra to a line parallel to the posterior portion of the slipped vertebral body and the anteroposterior dimension of the slipped vertebra

All patients underwent reconstruction CT scans (Siemens SOMATOM Sensation ver. 16, Siemens Asahi Meditec Inc., Shinagawa, Tokyo, Japan) of instrumented levels after surgery. Pedicle screw perforations of cervical pedicles were evaluated by axial CT images with a slice thickness of $1.25 \mathrm{~mm}$. Screw insertion status was classified as follows: grade 1 (no perforation), the screw is accurately inserted in pedicle; grade 2 (minor perforation), perforation of less than $50 \%$ of screw diameter; grade 3 (major perforation), perforation of $50 \%$ of screw diameter or more.

\section{3) Statistical analysis}

All data were analyzed using the Wilcoxon signed rank test using SPSS ver. 20 (SPSS Japan Inc., IBM, Tokyo, Japan), and the level of statistical significance was set at $p<$ 0.05 . 
Table 1. Clinical profiles and details of surgical procedures

\begin{tabular}{|c|c|c|c|c|c|c|c|c|}
\hline Case & $\begin{array}{c}\text { Age at } \\
\text { surgery (yr) }\end{array}$ & Sex & Preoperative symptom & $\begin{array}{r}\text { Duration of } \\
\text { disease (mo) }\end{array}$ & $\begin{array}{l}\text { Involved } \\
\text { level }\end{array}$ & $\begin{array}{l}\text { Range of } \\
\text { fusion }\end{array}$ & $\begin{array}{c}\text { Level of } \\
\text { laminoplasty }\end{array}$ & $\begin{array}{l}\text { Follow-up } \\
\quad(\mathrm{mo})\end{array}$ \\
\hline 1 & 85 & $\mathrm{M}$ & $\begin{array}{l}\text { MH, GD, MD (B.ULL), SD } \\
\text { (B.UL) }\end{array}$ & 2 & $\mathrm{C} 3 / 4$ & $\mathrm{C} 3-4$ & $\mathrm{C} 3-6$ & 12 \\
\hline 2 & 71 & $\mathrm{~F}$ & $\begin{array}{l}\text { MH, GD, BRD, MD (B.ULL), } \\
\text { SD (B.UL) }\end{array}$ & 12 & $\mathrm{C} 4 / 5$ & $\mathrm{C} 3-5$ & $\mathrm{C} 3-7$ & 15 \\
\hline 3 & 69 & M & MH, MD (B.UL), SD (L.UL) & 6 & $\mathrm{C} 3 / 4$ & C3-4 & C3-6 & 12 \\
\hline 4 & 77 & $\mathrm{~F}$ & $\begin{array}{l}\text { MH, GD, MD (B.ULL), SD } \\
\text { (B.UL) }\end{array}$ & 6 & $\mathrm{C} 4 / 5$ & C3-6 & C3-6 & 19 \\
\hline 5 & 76 & M & MD (B.UL), & N/A & $\mathrm{C} 5 / 6$ & C5-6 & C3-6 & 83 \\
\hline 6 & 72 & $\mathrm{M}$ & $\begin{array}{l}\text { MH, GD, BRD, MD (B.ULL), } \\
\text { SD (B.ULL) }\end{array}$ & N/A & $\mathrm{C} 4 / 5$ & C3-7 & $\mathrm{C} 3-7$ & 50 \\
\hline 7 & 55 & $\mathrm{M}$ & SD (R.UL) & N/A & $\mathrm{C} 6 / 7$ & C6-7 & $\mathrm{C} 3-7$ & 60 \\
\hline 8 & 75 & $\mathrm{M}$ & MH, MD (B.ULL), SD (L.UL) & 4 & $\mathrm{C} 5 / 6$ & C5-6 & $\mathrm{C} 3-7$ & 15 \\
\hline 9 & 80 & M & $\begin{array}{l}\text { MH, GD, BRD, MD (B.UL), } \\
\text { SD (B.UL) }\end{array}$ & 2 & $\mathrm{C} 3 / 4$ & $\mathrm{C} 3-5$ & $\mathrm{C} 3-5$ & 12 \\
\hline 10 & 69 & $\mathrm{M}$ & $\begin{array}{l}\text { MH, GD, MD (B.UL), SD } \\
\text { (B.UL) }\end{array}$ & 4 & $\mathrm{C} 5 / 6$ & $\mathrm{C} 4-6$ & $\mathrm{C} 4-6$ & 19 \\
\hline 11 & 78 & $\mathrm{~F}$ & MH, GD, BRD, SD (L.UL) & 96 & $\mathrm{C} 3 / 4$ & C3-4 & $\mathrm{C} 3-5$ & 12 \\
\hline 12 & 76 & $\mathrm{M}$ & MH, SD (B.UL) & 4 & $\mathrm{C} 4 / 5$ & C4-6 & $\mathrm{C} 4-5$ & 12 \\
\hline 13 & 72 & $\mathrm{~F}$ & MH, SD (B.ULL) & 1 & $\mathrm{C} 3 / 4$ & $\mathrm{C} 3-6$ & C3-6 & 12 \\
\hline
\end{tabular}

MH: Myelopathy hand, GD: Gait disturbance, MD: Motor deficit, B: Bilateral, ULL: Upper and lower limbs, SD: Sensory disturbance, UL: Upper limb, BRD: Bladder and rectal disturbance, L: Left, R: Right, LL: Lower limb, N/A: Not available.

\section{Results}

The patients' follow-up periods ranged from 12 to 83 months (mean, $25.6 \pm 23.3$ months). The patients' details are shown in Table 1. A total of 55 CPSs from C2-7 were inserted using the CT-based navigation system. The mean number for the fused level was 1.8 intervertebral levels (range, 1-4 levels): C3-4, n = 3; C5-6, $\mathrm{n}=2$; C6-7, $\mathrm{n}=$ $1 ; \mathrm{C} 3-5, \mathrm{n}=2 ; \mathrm{C} 4-6, \mathrm{n}=2 ; \mathrm{C} 3-6, \mathrm{n}=2$; and $\mathrm{C} 3-7, \mathrm{n}=1$.

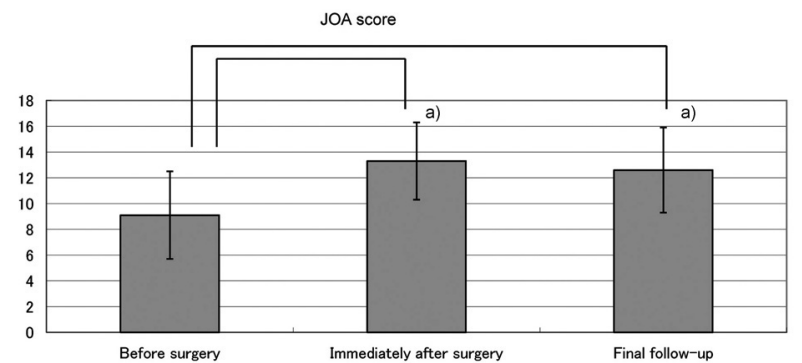

Fig. 1. Preoperative and postoperative Japanese Orthopedic Association (JOA) scores. The mean JOA score improved significantly $(p=0.005)$ immediately after surgery and was maintained to the final follow-up $(p=0.009) .{ }^{\text {a) }} p<0.05$.
The mean number for the laminoplasty level was 2.9 intervertebral levels (range, 1 to 4 levels): $\mathrm{C} 4-5, \mathrm{n}=1 ; \mathrm{C} 3-5, \mathrm{n}$ $=2 ; \mathrm{C} 4-6, \mathrm{n}=1 ; \mathrm{C} 3-6, \mathrm{n}=5$; and $\mathrm{C} 3-7, \mathrm{n}=4$.

\section{Clinical results}

The average surgical time was 225 minutes (range, 117 to 425 minutes). The average blood loss was $228 \mathrm{ml}$ (range, 50 to $520 \mathrm{ml})$.

The mean JOA scores before and immediately after surgery were $9.1 \pm 3.4$ points (range, 2 to 15.5 points) and $13.3 \pm 3.0$ points (range, 7.5 to 16.5 points), respectively. At the final follow-up, the mean JOA score was $12.6 \pm 3.3$ points (range, 7.5 to 16.5 points). The mean JOA score immediately after surgery was significantly improved $(p=0.005)$ and maintained to the final follow-up $(p=0.009)$ (Fig. 1). The recovery rate was $55.9 \%$ (range, $36.7 \%$ to $84.2 \%$ ) immediately after surgery, which was maintained at $47.1 \%$ at the final follow-up (range, $-16.7 \%$ to $78.6 \%$ ). 


\section{Radiographic results}

The mean $\mathrm{C} 2-7$ lordotic angle of the neutral position changed from $8.8^{\circ} \pm 11.0^{\circ}$ (range, $-10^{\circ}$ to $20^{\circ}$ ) to $5.6^{\circ} \pm$ $12.0^{\circ}$ (range, $-22^{\circ}$ to $22^{\circ}$ ) immediately after surgery and $5.3^{\circ}$ $\pm 10.9^{\circ}$ (range, $-15^{\circ}$ to $18^{\circ}$ ) at the final follow-up. Statistical analysis did not show any significant difference between the preoperative and immediately after surgery $\mathrm{C} 2-7$ angles $(p$ $=0.092)$. However, the mean $\mathrm{C} 2-7$ lordotic angle at the final follow-up decreased significantly $(p=0.021)$. The ROM of the cervical spine at $\mathrm{C} 2-7$ decreased significantly from $37.8^{\circ} \pm 10.9^{\circ}$ (range, $21^{\circ}$ to $51^{\circ}$ ) to $8.0^{\circ} \pm 6.4^{\circ}$ (range, $0^{\circ}$ to $\left.18^{\circ}\right)(p=0.043) ; \% \mathrm{ROM}$ was $21.8 \%$ (range, $0 \%$ to $40.6 \%$ ).

The mean percentages of slip of the unstable intervertebrae were as follows: before surgery in flexion, $17.0 \% \pm$ $13.0 \%$ (range, $0 \%$ to $40 \%$ ); in the neutral position, $9.1 \% \pm$ $15.2 \%$ (range, $-23 \%$ to $40 \%$ ); in extension, $5.5 \% \pm 12.7 \%$ (range, $-23 \%$ to $32 \%$ ); immediately after surgery in the neutral position, $3.2 \% \pm 9.3 \%$ (range, $-20 \%$ to $17 \%$ ); at the final follow-up in the neutral position, $3.5 \% \pm 9.4 \%$ (range, $-20 \%$ to $21 \%$ ). There were significant improvements immediately after surgery $(p=0.017)$ and at the final follow-up $(p$
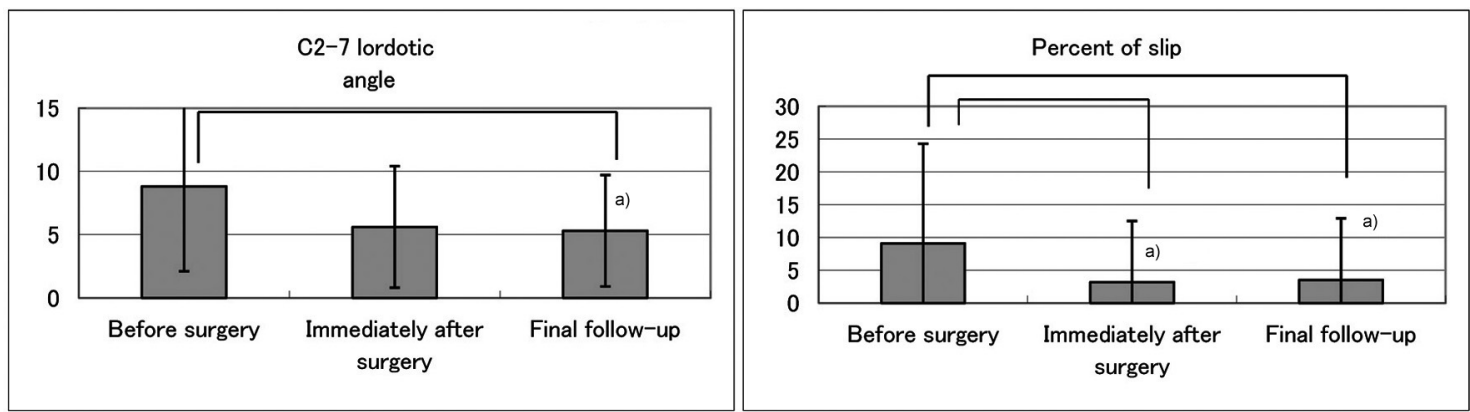

Fig. 2. Preoperative and postoperative radiographic evaluation. The mean $C 2-7$ lordotic angle of the neutral position changed from $8.8^{\circ} \pm 11.0^{\circ}$ to $5.6^{\circ} \pm 12.0^{\circ}$ at the final follow-up. The mean percentage of slip improved significantly immediately after surgery $(p=0.0017)$ and at the final follow-up $(p=0.0017)$. a) $p<0.05$.
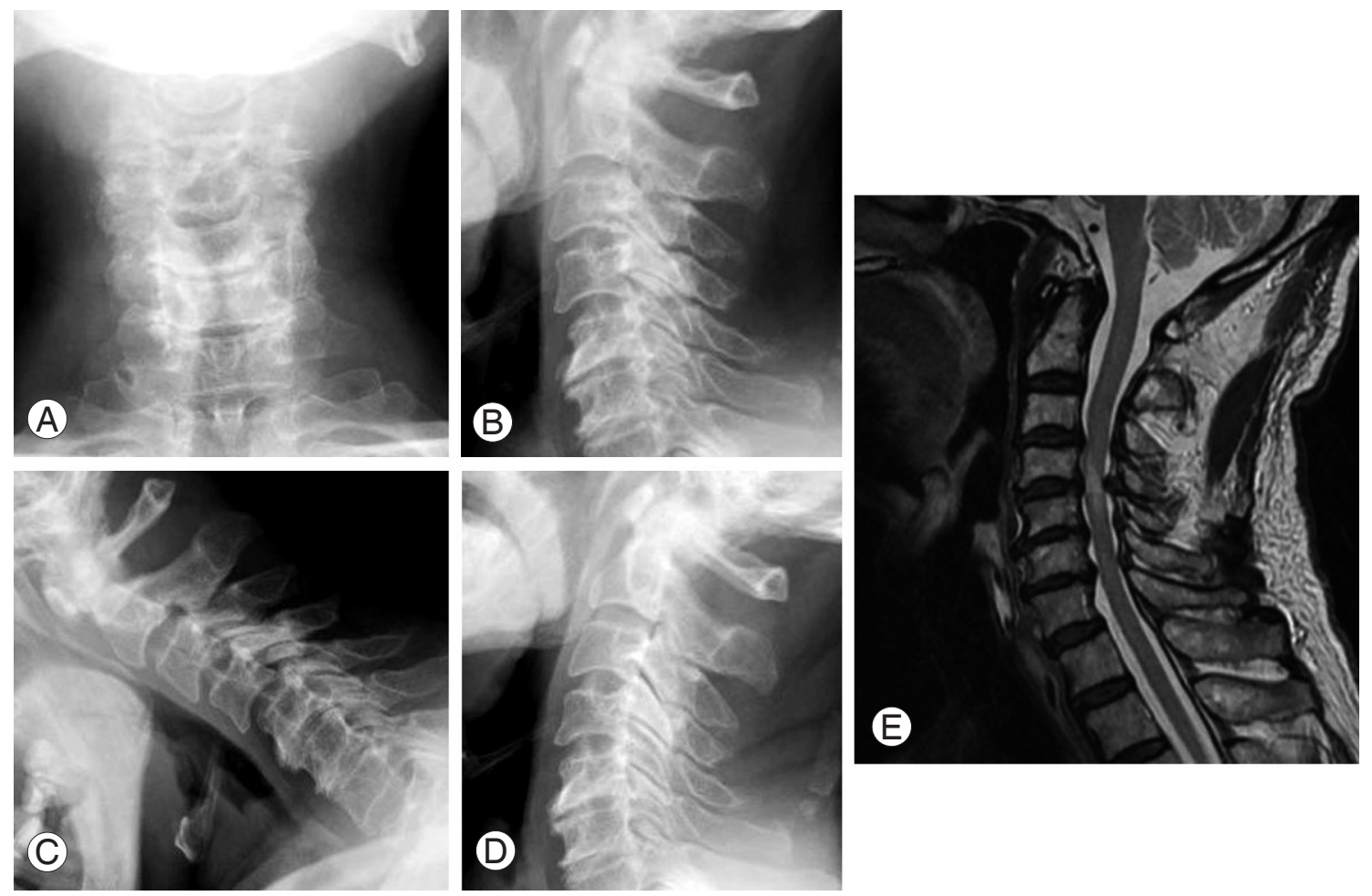

Fig. 3. Cervical spondylotic myelopathy in a 76-year-old man with instability (case 12). Preoperative radiographs showed percentages of slip of $18 \%, 0 \%$, and $0 \%$ in flexion, and the neutral and extension positions, respectively; the slip angles were $-11^{\circ},-1^{\circ}$, and $6^{\circ}$, respectively at the $C 4 / 5$ level (A-D). Preoperative magnetic resonance imaging indicated spinal cord compression and signal change at the $\mathrm{C} 4 / 5$ level (E). 
$=0.017)$ compared with the neutral position before surgery

(Fig. 2). The difference in slip angle between the maximum flexion and extension of unstable intervertebrae changed from $9.0^{\circ} \pm 5.5^{\circ}$ (range, $2^{\circ}$ to $20^{\circ}$ ) before surgery to $1.6^{\circ} \pm$ $1.9^{\circ}$ (range, $0^{\circ}$ to $5^{\circ}$ ) at the final follow-up. The difference in slip angle showed significant improvement $(p=0.043)$.

The rate of grade 3 pedicle screw perforations was $10.9 \%$ (6/55), whereas the rate of grades 2 and 3 combined was $20.0 \%(11 / 55)$. Five screws were perforated laterally, and 6 were perforated medially. No newly developed neurologic deficits occurred after surgery. No deaths occurred, or no instrumentation-related neural or vascular injuries were noted. One C5 palsy and 1 deep vein thrombosis occurred.
All 10 patients that could be evaluated by CT more than 6 months after surgery achieved bony fusion. The reclosure rate of laminoplasty was measured at $0 \%$.

\section{Case presentation}

Cervical spondylotic myelopathy in a 76-year-old man with instability (case 12). Preoperative radiographs showed percentages of slip of $18 \%, 0 \%$, and $0 \%$ in flexion, and the neutral and extension positions, respectively; the slip angles were $-11^{\circ},-1^{\circ}$, and $6^{\circ}$, respectively. Preoperative magnetic resonance imaging indicated spinal cord compression and signal change at the $\mathrm{C} 4 / 5$ level (Fig. 3). Postoperative ra-
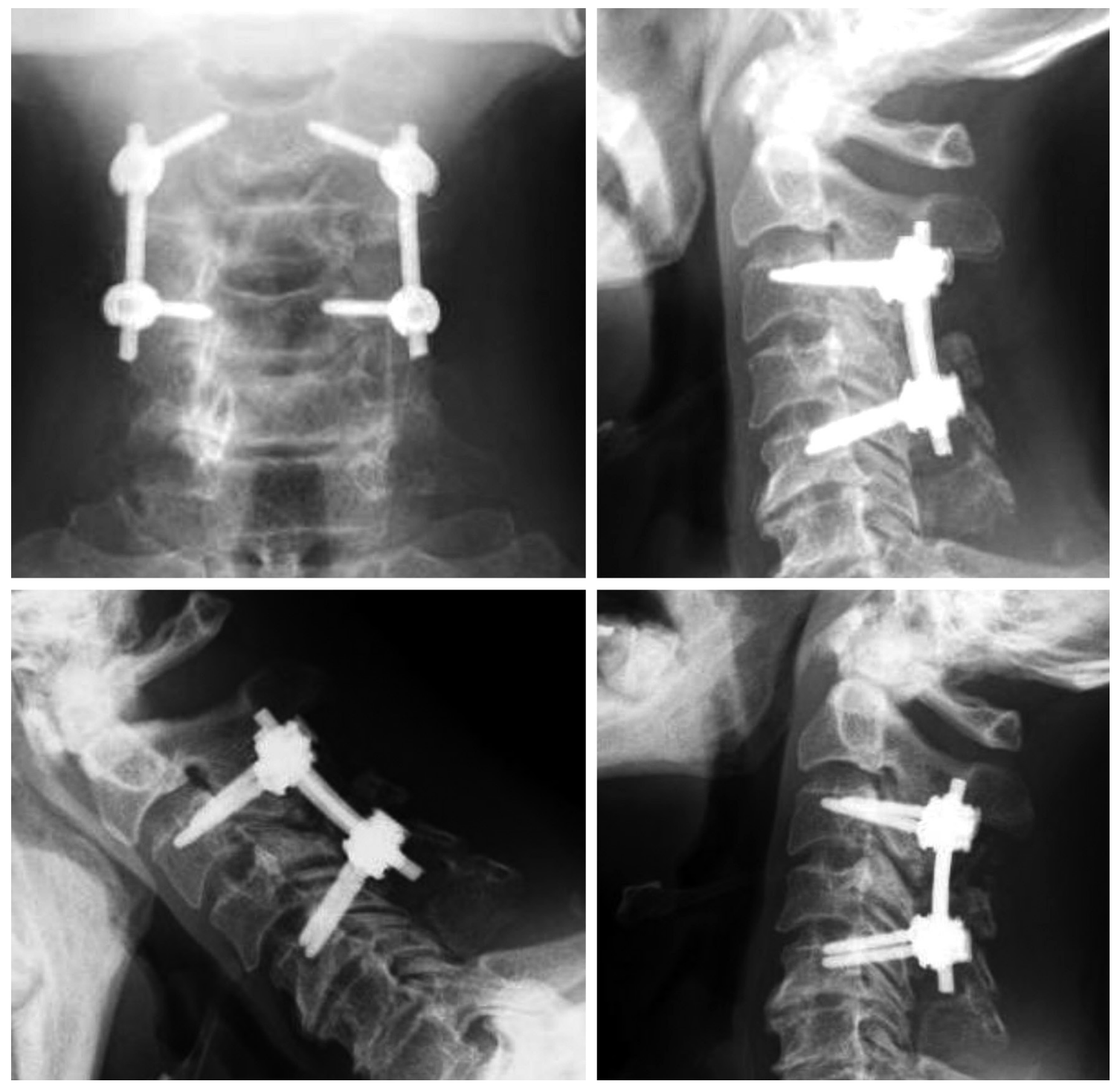

Fig. 4. Postoperative radiographs 1 year after surgery in case 12 . Postoperative radiographs indicated accurate penetration of the screws with good positioning. Cervical spinal alignment was good. The percentage of slip was corrected to $0 \%$. The range of motion of the cervical spine at $\mathrm{C} 2-7$ improved from $39^{\circ}$ to $7^{\circ}$. There were no neurovascular complications. Japanese Orthopedic Association score in the patient improved from 7.5 to 12 points 1 year after surgery. 
diographs indicated accurate penetration of the screws with good positioning. Cervical spinal alignment was good. The percentage of slip was corrected to $0 \%$. The range of motion of the cervical spine at $\mathrm{C} 2-7$ improved from $39^{\circ}$ to $7^{\circ}$. There were no neurovascular complications. JOA score in the patient improved from 7.5 to 12 points 1 year after surgery (Fig. 4). Postoperative computed tomography shows that pedicle screws were inserted bilaterally into $\mathrm{C} 3$ and $\mathrm{C} 5$. Bilateral C3 and C5 pedicle screws were accurately inserted into the pedicles (Fig. 5). Operative photo was shown in Fig. 6.

\section{Discussion}

Cervical fusion and spinal cord decompression are required for patients having myelopathy with cervical instability. In such cases, $\mathrm{ADF}$ or laminectomy with lateral mass screw fixation has been performed [8]. Cervical spine fixation using CPSs was first reported by Abumi et al. [9] and Jeanneret et al. [10] in 1994. Both reports describe cases of cervical instability caused by cervical trauma. Cervical spine fixation by CPS was introduced as a procedure for treating cervical instability of the middle and/or lower cervical spine caused by trauma; the importance of fixation by CPS for posterior cervical decompression and reconstruction was subsequently reported $[11,12]$.

The indications for CPSs have since been extended and now include symptoms such as RA, DSA, and spinal tumor [13-15]. Moreover, CPSs can achieve rigid fixation better than other cervical fixation methods $[16,17]$ and can be combined with posterior spinal cord decompression. The strong initial fixation eliminates the necessity of postoperative external fixation such as a halo vest or neck collar. Furthermore, patients can stand up and walk shortly after treatment. In our study, this procedure maintained rigid fixation postoperatively and improved clinical symptoms [18]. However, CPS insertion is technically difficult because the cervical pedicle diameter is narrow, especially from $\mathrm{C} 3$ to 6. Neurovascular complications, including vertebral artery

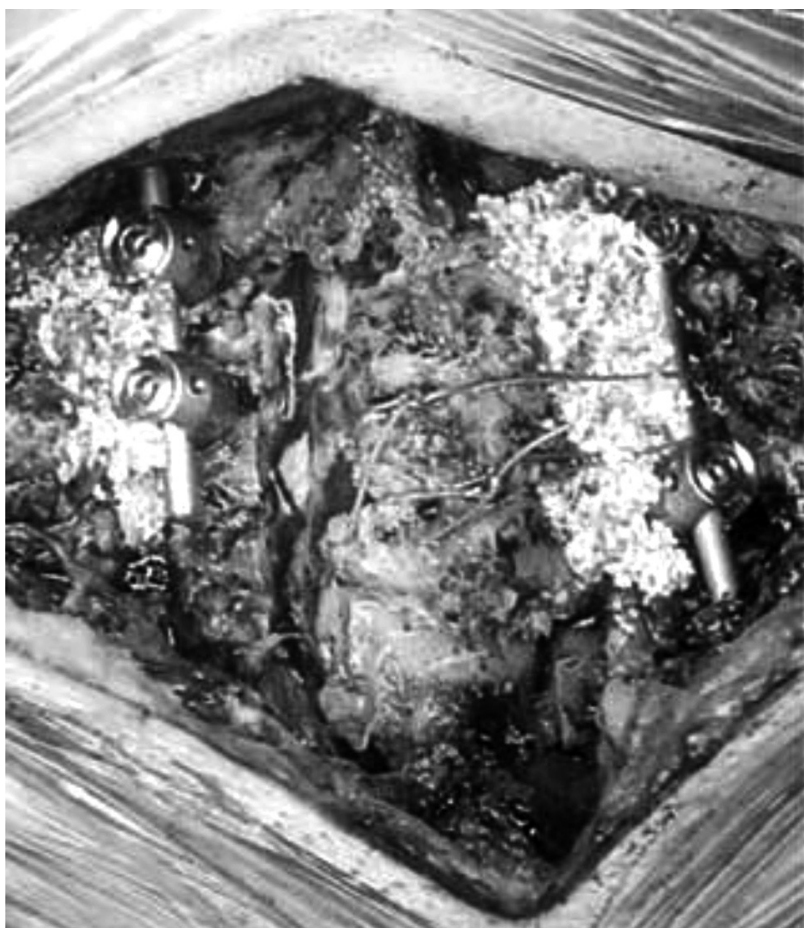

Fig. 6. Operative photo. Cervical spondylotic myelopathy in a female with instability was treated with cervical pedicle screw fixation in the bilateral $\mathrm{C} 3$, left $\mathrm{C} 4$, and right $\mathrm{C} 5$, combined with left open C3-6 laminoplasty.

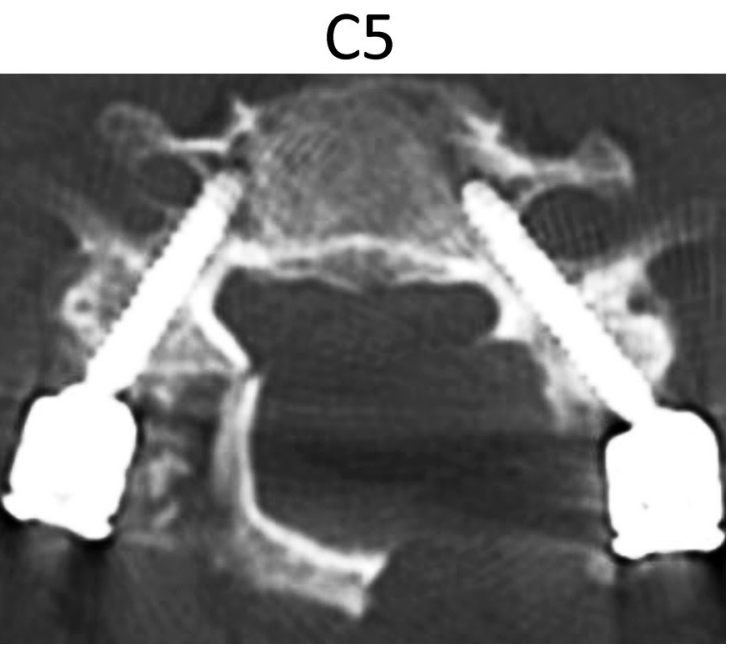

Fig. 5. Postoperative computed tomography. Pedicle screws were inserted bilaterally into $\mathrm{C} 3$ and $\mathrm{C} 5$. Bilateral $\mathrm{C} 3$ and $\mathrm{C} 5$ pedicle screws were accurately inserted into the pedicles. 
tear, spinal cord injury, and nerve root injury, may occur [19]. To achieve more accurate and safe CPS insertion, our institution employs a CT-based navigation system [20,21].

In previous reports, the recovery rates of JOA scores ranged from $38.8 \%$ to $72.4 \%$ after $\mathrm{ADF}$ [22,23], $67 \%$ after laminoplasty and lateral mass screw fixation [24], and 61\% after laminoplasty and CPS fixation [25]. The recovery rates of JOA scores in the present study are similar to those reported previously; there are only small differences in cervical fixation procedures between the studies.

Kyphotic changes in the cervical spine after cervical spinal surgery are well known regardless of anterior and posterior procedures. Cabraja et al. [26] report that the loss of correction is higher in anterior procedures than in posterior ones. In our study, the $\mathrm{C} 2-7$ lordotic angle decreased significantly from the period before surgery to the final followup.

Due to severe spinal degeneration and the small anatomical size of the vertebra for CSM patients, CPS placement procedures are very technically demanding and pose the potential risk of neurovascular injuries. We perform CPS insertions with a CT-based navigation system to avoid neurovascular injuries and have achieved good results $[18,20]$. The previously reported perforation rates of CPS for RA, DSA, and spinal trauma are $0 \%$ to $22 \%$ [20,27], $6.1 \%$ [28], and $3.9 \%$ to $9.2 \%$ [29], respectively. Although the perforation rate in the present study is slightly higher than that reported previously, there were no serious complications. In our previous report comparing pedicle screw perforation rate with regard to the disease, the perforation rate for CSM was higher than those for spinal tumor, RA, and DSA [18]. However, strong deformities were observed, and pedicles sometimes became osteosclerotic in CSM patients. Therefore, the probe could not be inserted easily, which resulted in perforation despite the use of the CT-based navigation system. We should be careful not to cause perforations when inserting CPSs in CSM patients even if we use the CT-based navigation system. To avoid perforations in such conditions, the pedicle should be skipped or the fixation method should utilize a lateral mass screw or sublaminar cable.

This study has certain limitations, including the lack of a control group, the small number of patients, and short-term follow-up. However, we achieved good improvement of both clinical and radiological results in this study without worsening the patients' symptoms. Furthermore, laminoplasty with CPS is advantageous compared to laminectomy with fusion because of reduced postoperative epidural scar- ring.

\section{Conclusions}

Posterior CPS fixation combined with laminoplasty improved both clinical and radiological results in CSM patients with instability in this study without any instrumentrelated neurovascular complications. This method has been shown to be an effective surgical procedure for treating CSM patients with cervical spinal instability.

\section{REFERENCES}

1. Emery SE, Bohlman HH, Bolesta MJ, Jones PK. Anterior cervical decompression and arthrodesis for the treatment of cervical spondylotic myelopathy. Two to seventeen-year follow-up. J Bone Joint Surg Am 1998;80:941-51.

2. Chagas H, Domingues F, Aversa A, Vidal Fonseca AL, de Souza JM. Cervical spondylotic myelopathy: 10 years of prospective outcome analysis of anterior decompression and fusion. Surg Neurol 2005;64 Suppl 1:S1:30-5.

3. Sekhon LH. Posterior cervical decompression and fusion for circumferential spondylotic cervical stenosis: review of 50 consecutive cases. J Clin Neurosci 2006;13:23-30.

4. Kumar VG, Rea GL, Mervis LJ, McGregor JM. Cervical spondylotic myelopathy: functional and radiographic long-term outcome after laminectomy and posterior fusion. Neurosurgery 1999;44:771-7.

5. White AA, Panjabi MM. Clinical biomechanics of the spine. 2nd ed. Philadelphia: Lippincott; 1990.

6. Hirabayashi K, Watanabe K, Wakano K, Suzuki N, Satomi K, Ishii Y. Expansive open-door laminoplasty for cervical spinal stenotic myelopathy. Spine (Phila Pa 1976) 1983;8:693-9.

7. Japanese Orthopedic Association. Scoring system for cervical myelopathy. J Jpn Orthop Assoc 1994;68:490503.

8. Koller H, Hempfing A, Ferraris L, Maier O, Hitzl W, Metz-Stavenhagen P. 4- and 5-level anterior fusions of the cervical spine: review of literature and clinical results. Eur Spine J 2007;16:2055-71.

9. Abumi K, Itoh H, Taneichi H, Kaneda K. Transpedicular screw fixation for traumatic lesions of the middle and lower cervical spine: description of the techniques 
and preliminary report. J Spinal Disord 1994;7:19-28.

10. Jeanneret B, Gebhard JS, Magerl F. Transpedicular screw fixation of articular mass fracture-separation: results of an anatomical study and operative technique. J Spinal Disord 1994; 7:222-9.

11. Abumi K, Kaneda K. Pedicle screw fixation for nontraumatic lesions of the cervical spine. Spine (Phila Pa 1976) 1997;22:1853-63.

12. Abumi K, Kaneda K, Shono Y, Fujiya M. One-stage posterior decompression and reconstruction of the cervical spine by using pedicle screw fixation systems. J Neurosurg 1999;90:19-26.

13. Ludwig SC, Kramer DL, Vaccaro AR, Albert TJ. Transpedicle screw fixation of the cervical spine. Clin Orthop Relat Res 1999;(359):77-88.

14. Ebraheim NA, Xu R, Knight T, Yeasting RA. Morphometric evaluation of lower cervical pedicle and its projection. Spine (Phila Pa 1976) 1997;22:1-6.

15. Panjabi MM, Shin EK, Chen NC, Wang JL. Internal morphology of human cervical pedicles. Spine (Phila Pa 1976) 2000;25:1197-205.

16. Yoshimoto H, Sato S, Hyakumachi T, Yanagibashi Y, Kanno T, Masuda T. Clinical accuracy of cervical pedicle screw insertion using lateral fluoroscopy: a radiographic analysis of the learning curve. Eur Spine J 2009; 18:1326-34.

17. Neo M, Sakamoto T, Fujibayashi S, Nakamura T. The clinical risk of vertebral artery injury from cervical pedicle screws inserted in degenerative vertebrae. Spine (Phila Pa 1976) 2005;30:2800-5.

18. Uehara M, Takahashi J, Hirabayashi H, et al. Perforation rates of cervical pedicle screw insertion by disease and vertebral level. Open Orthop J 2010;4:142-6.

19. Rath SA, Moszko S, Schäffner PM, et al. Accuracy of pedicle screw insertion in the cervical spine for internal fixation using frameless stereotactic guidance. J Neurosurg Spine 2008;8:237-45.

20. Takahashi J, Shono Y, Nakamura I, et al. Computer- assisted screw insertion for cervical disorders in rheumatoid arthritis. Eur Spine J 2007;16:485-94.

21. Ogihara N, Takahashi J, Hirabayashi H, Hashidate H, Kato H. Long-term results of computer-assisted posterior occipitocervical reconstruction. World Neurosurg 2010;73:722-8.

22. Huang JJ, Niu CC, Chen LH, Lai PL, Fu TS, Chen WJ. Anterior cervical spinal surgery for multilevel cervical myelopathy. Chang Gung Med J 2004;27:531-41.

23. Dai LY, Jiang LS. Anterior cervical fusion with interbody cage containing beta-tricalcium phosphate augmented with plate fixation: a prospective randomized study with 2-year follow-up. Eur Spine J 2008;17:698705.

24. Chen HC, Chang MC, Yu WK, Wang ST, Liu CL, Chen TH. Lateral mass anchoring screws for cervical laminoplasty: preliminary report of a novel technique. J Spinal Disord Tech 2008;21:387-92.

25. Liu Y, Hu JH, Yu KY. Pedicle screw fixation for cervical spine instability: clinical efficacy and safety analysis. Chin Med J (Engl) 2009;122:1985-9.

26. Cabraja M, Abbushi A, Koeppen D, Kroppenstedt S, Woiciechowsky C. Comparison between anterior and posterior decompression with instrumentation for cervical spondylotic myelopathy: sagittal alignment and clinical outcome. Neurosurg Focus 2010;28:E15.

27. Ito H, Neo M, Yoshida M, Fujibayashi S, Yoshitomi $\mathrm{H}$, Nakamura T. Efficacy of computer-assisted pedicle screw insertion for cervical instability in RA patients. Rheumatol Int 2007;27:567-74.

28. Yuzawa Y, Kamimura M, Nakagawa H, et al. Surgical treatment with instrumentation for severely destructive spondyloarthropathy of cervical spine. J Spinal Disord Tech 2005;18:23-8.

29. Yukawa Y, Kato F, Ito K, et al. Placement and complications of cervical pedicle screws in 144 cervical trauma patients using pedicle axis view techniques by fluoroscope. Eur Spine J 2009;18:1293-9. 